\title{
Oral Pancreatic Cancer Vaccine V3-P
}

National Cancer Institute

\section{Source}

National Cancer Institute. Oral Pancreatic Cancer Vaccine V3-P. NCI Thesaurus. Code C150400.

An orally bioavailable, therapeutic cancer vaccine composed of the carbohydrate antigen sialyl-Lewis A (carbohydrate antigen 19-9; CA19.9; CA19-9) that is derived from pooled blood of pancreatic cancer patients, with potential immunomodulating activity. Upon oral administration of the oral pancreatic cancer vaccine V3-P, the CA19.9 antigens may stimulate the host immune system to mount a cytotoxic T-lymphocyte (CTL)-mediated immune response against pancreatic cancer cells expressing the CA19.9 antigen. CA19.9 is overexpressed on a number of different tumor cell types and plays a key role in tumor cell survival and metastasis. 